\title{
Realising a climate-resilient UK electricity and gas system
}

Alexandre Metz Dipl Ing

MSc student, Energy Futures Lab, Imperial College London, London, UK Geoff Darch BSc (Hons), MSc, PhD, CSci, MCIWEM, C.WEM, FRMetS Principal Consultant, Atkins, Peterborough, UK

\section{Mark Workman PhD}

Executive Analyst, Energy Research Partnership, London, UK; Researcher, Imperial College London, London, UK

The risks presented by climate change mean that there is a need to future-proof the UK's energy (electricity and natural gas) infrastructure. The scale of investment required is estimated at more than f200 billion by 2030. Although there are a variety of funding sources available, increasing proportions of infrastructure investment are now being funded by the private sector. Therefore, it will be necessary to find ways to incentivise private investors to accommodate for adaptation requirements in their decision-making processes. Research was undertaken to explore the UK energy infrastructure under the following three main lenses. (a) What technical aspects of energy infrastructure need to consider the effects of climate change? (b) What investment is required in the near future to adapt to climate change? (c) What types of policy could create reliable signals for investment in climate change adaptation? This paper presents key findings and considerations for policy covering the three questions above: (a) there are data gaps, interdependencies not effectively assessed and techniques available but not yet adopted; (b) the investment community suffers from a lack of climate change expertise and a short-term mindset; and (c) there is a need for a clearer policy vision and greater collaboration.

\section{Introduction}

The projected impacts of climate change and infrastructure interdependencies on UK resilience are inherently uncertain, making the task of future-proofing (i.e. developing methods to minimise the effects of future events) the UK energy system highly problematic. Adaptation to climate change is defined as 'the process of adjustment to actual or expected climate and its effects' (IPCC, 2014). The UK energy infrastructure that is covered by this paper refers to power generation as well as electricity and natural gas networks in the UK. The scale of investment required for the overall UK energy infrastructure is estimated at more than $£ 200$ billion by 2030 (HM Treasury, 2013b). Although there are substantial sources of funding available, it is argued that the UK energy market in its present form, with the conflicting priorities across stakeholders, creates inefficiencies and obstacles to addressing energy system resilience to climate change. With increasing proportions of infrastructure investment being funded by the private sector, it is necessary to find ways to incentivise private investors to accommodate for adaptation requirements in their decision-making processes. This will bring substantial efficiencies: it has been estimated that 'up to $65 \%$ of the loss expected to 2030 - under a high climate change scenario - can be averted cost effectively through adaptation investment' (WEF, 2014).
The purpose of this paper was to explore the adaptation requirements of the UK energy infrastructure under the following three main lenses. (a) What technical aspects of energy infrastructure need to consider the effects of climate change? (b) What investment is required in the near future to adapt to climate change? (c) What types of policy could create reliable signals for investment in climate change adaptation?

Section 2 outlines the methodology developed during the research. Then, Section 3 presents the results of the initial research phase which involved a literature review concerning the overall issues regarding climate change impacts on UK energy infrastructure, as well as a collection of quantitative data on the scale of investment and sources of financing. The key findings from the interviews are discussed in Section 4, before policy considerations are raised in Section 5. The research is then summarised in Section 6.

\section{Methodology}

\subsection{Literature review}

During the preliminary phase, the literature covering the overall issues of climate change risks and adaptation, as well as their impacts on UK energy infrastructure, was reviewed. Papers ranged from theoretical and mathematical assessments 
of risks to practical, engineering impacts on the energy infrastructure, as well as policy frameworks presenting adaptation decision-making processes.

This literature review highlighted the amount of work already done in assessing climatic risks and impacts on the energy infrastructure, as well as in the decision-making processes; it concluded that there was a gap between research theory and industry practice, which was further explored during the interview phase.

\subsection{Quantitative analysis: data collection}

To undertake quantitative analysis, a core set of data, regarding both the scale of investment and the sources of finance in UK energy infrastructure, was established from the existing literature and updated whenever additional information was found with the help of stakeholders. Cross-analysis was conducted any time when different sources presented the same type of data; when a difference in numbers was spotted which was the case for data prior to 2010 - priority was given to official data from government bodies, such as the Office for National Statistics, the Department of Energy and Climate Change (DECC) and HM Treasury.

\subsection{Qualitative analysis: semi-structured interviews}

With an academic foundation of the state of the UK adaptation agenda, decision-making processes and the scale of investment necessary, interviews were then conducted with industry stakeholders to compare qualitatively their experiences relative to the conclusions in the literature. Semi-structured interviews were conducted to ensure that there was sufficient direction to get the main research questions answered, while allowing flexibility for the interviewee to raise additional issues that the interviewer may not have anticipated (Hoggart et al., 2002). As semi-structured interviews encourage two-way communication, they allow characterisation of how different stakeholders frame the subject matter whether they be engineers, investors or regulators (Saunders et al., 2002). A weakness of semi-structured interviews is the relatively small sample size; however, the method yields the above benefits over a larger, more shallow survey.

The interviewees were representative of the different stakeholders of the sector. Twenty-two interviewees were questioned and grouped into three main communities: the engineering community (11 interviewees were design engineers), the investment community (eight interviewees were investors and consultants working closely with energy project financiers) and the regulatory community (three interviewees were regulators and policymakers). The interview process lasted from 10 July to 8 August 2014. Since some interviewees refused to be directly quoted, no quotes have been directly attributed to any interviewee for consistency. Interviewees' statements were weighted according to the relative importance conveyed by the interviewee (Gillham, 2000); the sector average was then expressed in percentage terms to give the same importance to the three communities. This allowed displaying the relatively unstructured information given by interviewees in a more visual, coherent way. The interviewee experiences could thus be compared with quantitative data and any gap coming from the engineering, investment or regulatory communities were discussed.

\section{Research phase}

\subsection{The UK energy infrastructure under climate change disruption}

The literature review helped frame the study (Section 3.1.1) before highlighting the risks arising from climate change (Section 3.1.2) and the interdependencies with other sectors (Section 3.1.3).

\subsubsection{The UK energy infrastructure}

The UK energy infrastructure that is covered by this paper refers to power generation as well as electricity and natural gas networks in the UK. The UK electricity infrastructure encompasses (Defra, 2011, 2012a; NG, 2010a; PwC, 2010): a generation capacity of $89 \mathrm{GW}$ with 134 power plants; a national transmission grid with $25000 \mathrm{~km}$ of high-voltage overhead lines and 1500 substations; regional distribution networks with $800000 \mathrm{~km}$ of overhead lines and underground cables; 5000 primary high-voltage and 230000 low-voltage substations. Likewise, the UK natural gas infrastructure encompasses (NG, 2010b; PwC, 2010; URS, 2010) offshore production facilities with processing terminals; liquefied natural gas storage terminals; a national transmission grid with $7000 \mathrm{~km}$ of pipework; and regional distribution networks made of local transmission systems, intermediate-, medium- and low-pressure systems, with $130000 \mathrm{~km}$ of pipework

\subsubsection{Climate change risks and impacts on energy infrastructure}

It has been scientifically proven that climate change is happening now: the Intergovernmental Panel on Climate Change (IPCC) Working Group I concluded that 'since the 1950s, many of the observed changes are unprecedented over decades to millennia. The atmosphere and ocean have warmed, the amounts of snow and ice have diminished, sea level has risen, and the concentrations of greenhouse gases have increased' (IPCC, 2013). The UK Climate Projections 2009 (UKCP09, 2009) provides a range of potential changes to the climate for the next century, with associated probabilities based on current knowledge and climate modelling. Set under the Climate Change Act 2008 (2008), the first UK Climate Change Risk 
Assessment (CCRA) was based on UKCP09 (2009) and attributed a level of consequence and confidence to each potential risk with the help of organisations such as the Natural Hazards Partnership (Defra, 2012a, 2012b, 2012c). This assessment will be updated every 5 years, with the second UK CCRA due in 2017. National Policy Statements set the policy for major infrastructure planning applications. Six statements for energy infrastructure, produced by DECC, set out the government's policy for all planning aspects, one of which is adaptation to climate change (DECC, 2011a, 2011b). The National Adaptation Programme sets out what government, businesses and society are doing to adapt better to the changing climate. The first report was published in 2013 and will be reviewed every 5 years. The Adaptation Reporting Power was created in order to ensure climate change risk management is systematically undertaken by reporting authorities - which include energy service companies. The power was exercised for the first round of adaptation reports in 2012 and the second round is due in 2017 (Defra, 2011, 2013a; URS, 2010).

Climate change impacts on climate presented in these reports included rising air and water average temperatures, more extreme temperatures, more extreme weather events (e.g. precipitation, storms, droughts) and rising sea levels. Respective climate change impacts on the energy sector included fluvial and coastal flooding, efficiency losses, reduced availability of cooling water for power stations and subsidence.

\subsubsection{Interdependencies with other sectors}

Interdependencies between the energy sector and the water, transport and information and communications technology (ICT) sectors are of paramount importance (Figure 1). Failure in one sector can lead to a cascade of failures (URS, 2010) and must be included in risk management assessment. Poorly defined responsibility and coordination between operators of electricity and natural gas infrastructure could compromise resilience to climate change (Cimato and Mullan, 2010).

\subsection{Scale of investment and sources of finance}

Quantitative analysis reviewed the characteristics of energy infrastructure projects (Section 3.2.1) and compared historical with future investment (Section 3.2.2) before linking financing requirements to low-carbon scenarios and climate change adaptation (Section 3.2.3).

\subsubsection{Characteristics of energy infrastructure projects}

Energy infrastructure projects encompass structural and organisational characteristics. Although the overall energy sector is highly complex, each individual sector (i.e. electricity, natural gas) has a lower complexity: relatively few large companies (if not one monopoly) have been working with each other and with regulators for a long time. Energy infrastructure projects typically feature long decision timescales: 20/25-year contract periods for 50-year design lifetimes. A large up-front capital investment is required and expected to provide stable,

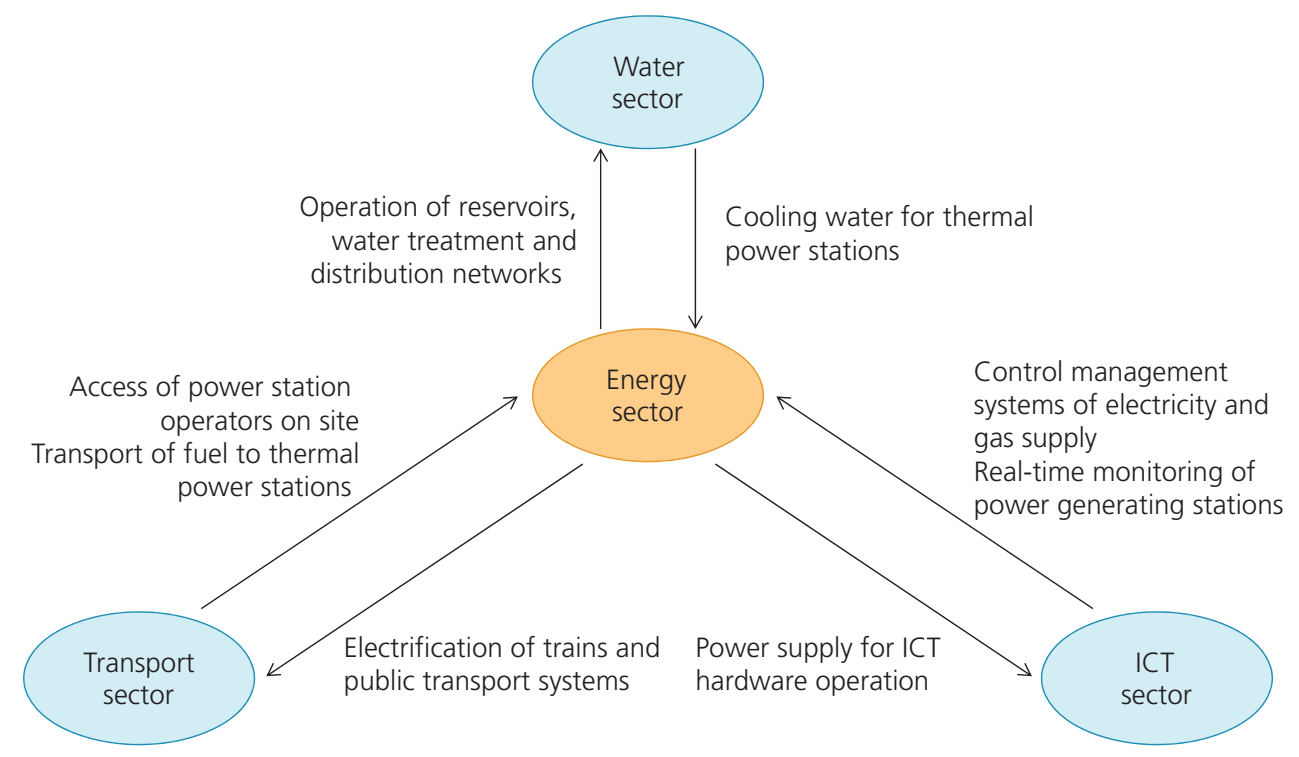

Figure 1. Examples of interdependencies between the energy sector and the water, transport and ICT sectors (Defra, 2013C; ITRC, 2014; Metz, 2014; URS, 2010) 
predictable long-term cash flows (Defra, 2012a, 2013b; Llewellyn Consulting, 2013).

\subsubsection{Historical trends and pipeline of scheduled projects}

Over the last decade, annual overall infrastructure investment increased by $10 \%$, from $£ 41$ billion in 2005 to $£ 45$ billion in 2012 (HM Treasury, 2012, 2013b). By far the biggest annual rise came from the energy sector with infrastructure investment increasing by $57 \%$ during the same period (Figure 2). While the annual overall infrastructure investment is expected to decrease by $40 \%$ over the next decade, the annual energy infrastructure investment is expected to more than double. The scale of investment for the overall UK energy infrastructure is estimated at more than $£ 200$ billion by 2030 (HM Treasury, 2013b). This results in the energy sector being an everincreasing share of overall infrastructure investment, from less than $20 \%$ before 2013 to more than $80 \%$ after 2020 .

Within the overall energy sector, the electricity sector receives most of the investment as compared with the gas sector. Over the last decade, investment in the gas sector has accounted for $15-20 \%$ of the overall energy sector - with the electricity sector accounting for the remaining proportion (DECC, 2012b; ONS, 2010, 2014). Within the next decade, the only investment in gas planned by the UK government's National Infrastructure Plan relates to gas transmission and distribution networks and amounts to $£ 11.7$ billion out of a total of nearly $£ 120$ billion - that is less than $10 \%$ (HM Treasury, 2013b). Within the next decade, it is expected that the generation sector will require more and more up-front investment, accounting for nearly two-thirds of the overall energy infrastructure investment pipeline of projects scheduled for 2013-2020 (Figure 3).

\subsubsection{Link to low-carbon scenarios and climate change adaptation investment}

On the basis of low-carbon scenarios presented by HM Treasury (2013a) and National Grid (NG, 2014), dominant future investments were compared according to their vulnerability to temperature (vertical axis in Figure 4) and to wind and precipitation (horizontal axis in Figure 4).

Most of the renewables are clustered on the right-hand side of the matrix - that is they are highly vulnerable to wind and precipitation. Yet their vulnerability to temperature varies: wind power is the most resilient renewable technology while solar power is the least. Respective projected investment is approximately three times higher for wind than for solar power: $£ 32-47$ billion for wind power compared with $£ 10-13$ billion for solar power depending on the scenario.

The generation technology which is the least vulnerable appears to be nuclear power, featuring a very low vulnerability to temperature and a medium vulnerability to wind and precipitation ( $£ 0-14$ billion projected investment depending on the scenario).

Projected investment in coal-fired power stations with carbon capture and storage technology accounts for $£ 0-7$ billion depending on the scenario. Although this technology is resilient to wind, precipitation and temperature, making it very attractive to develop, it may be compromised by the combination of the Emissions Performance Standard and the Carbon Price Floor, which will most likely prevent any new coal generation project and prompt the shutdown of most existing coal-fired power stations in the UK.

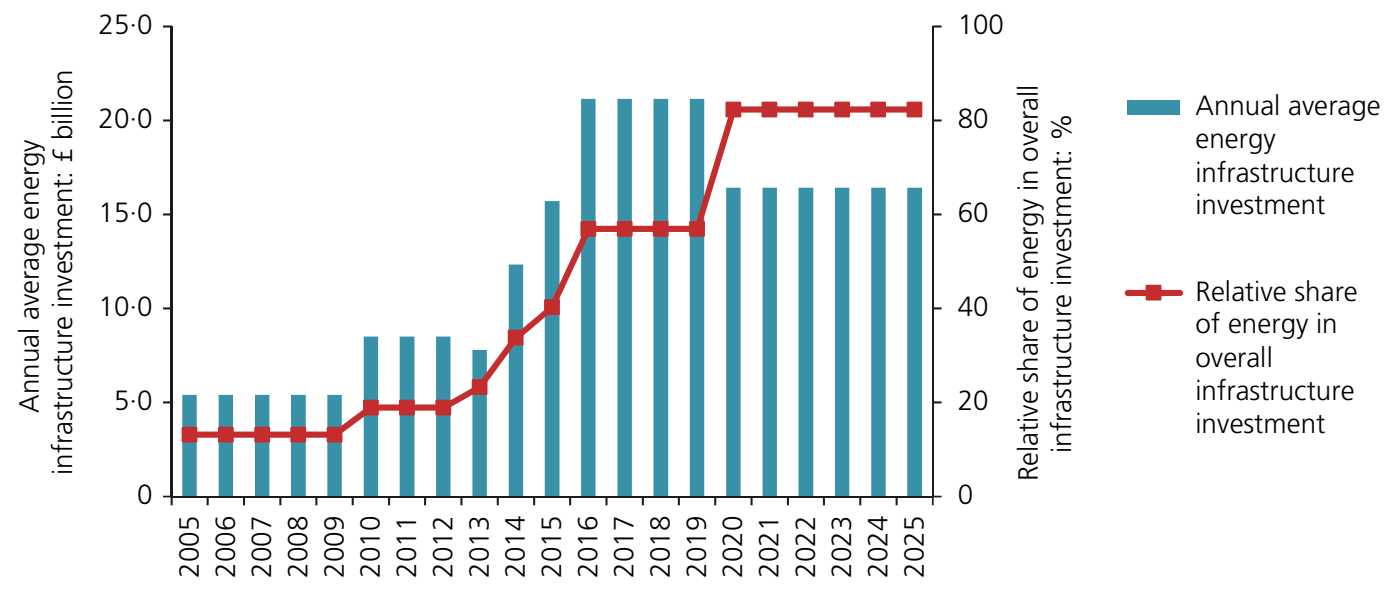

Figure 2. Annual average energy infrastructure investment (left axis, bars) and relative share in overall infrastructure investment (right axis, plot line), 2005-2025 (DECC, 2010, 2012a, 2013a;
HM Treasury, 2012a, 2013b; Metz, 2014). In the UK, the financial year $N$ runs from 1 April $N$ to 31 March $N+1$ 


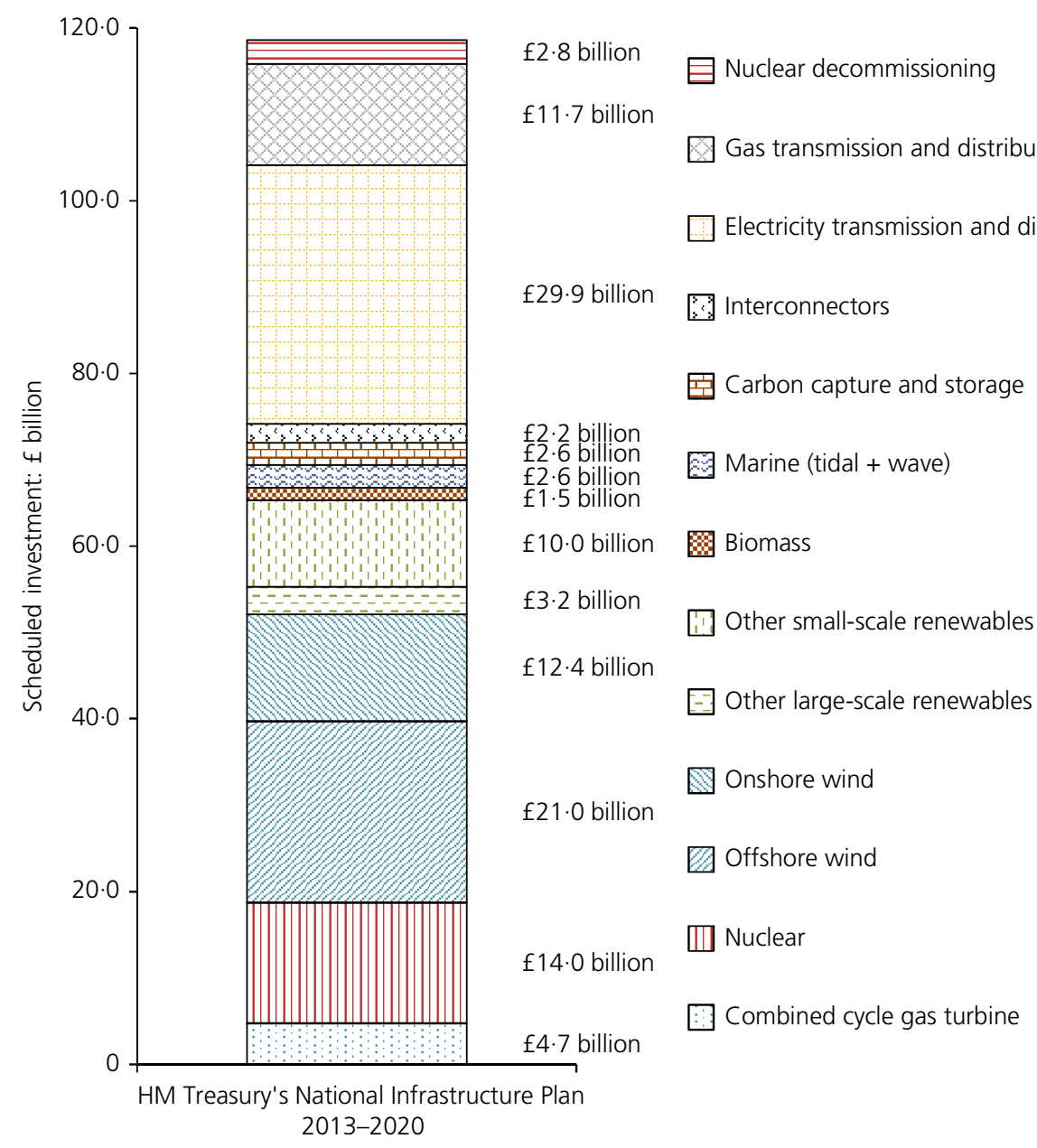

Figure 3. Scheduled energy mix infrastructure investment, 2013-2020 (HM Treasury, 2013b; Metz, 2014)

In terms of transmission and distribution networks, the electricity sector is more vulnerable to temperature (e.g. transmission capacity losses) than the gas sector; both being equally vulnerable to weather extremes such as flooding and storms. As discussed in Section 3.2.2, electricity networks require three times more investment than gas networks: $£ 28-30$ billion for electricity compared with $£ 11-12$ billion for gas depending on the scenario. Given that the authors anticipate using equal parts of both in the future, the amount of projected investment combined with the level of vulnerability to climate make electricity networks a priority in the adaptation agenda.

\section{Key findings}

Qualitative analysis based on interviews highlighted the following issues.

\subsection{Climate projections}

There is a lack of confidence in future projections of wind (speed and direction) as well as extreme weather events (storm and lightning). This creates uncertainty regarding future impacts on, for example, energy resource forecasting (e.g. wind energy, solar energy) and energy losses simulation (e.g. transmission lines). To address this, there is a need for improving communication between climate scientists, who outline a range of potential changes for the future, and design engineers, who are looking for an input to model infrastructure and do not always understand how to include future climate requirements in terms of design standards. As an interviewed expert on regulatory issues argued, 'when talking about extreme weather events, the problem is not the frequency, but rather the intensity of such events'. 


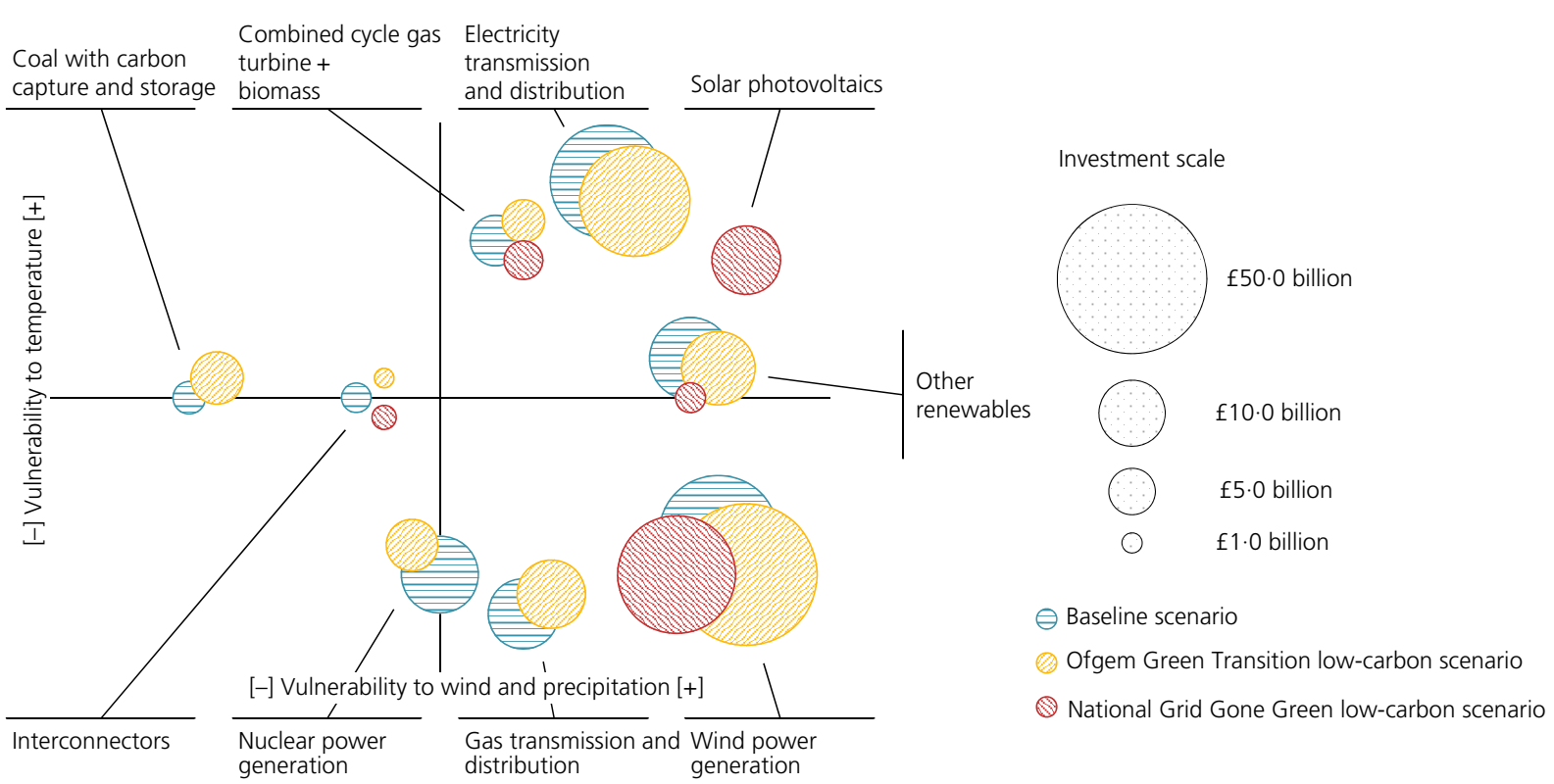

Figure 4. Dominant future investments (bubble size in $f$ billion) in energy infrastructure under a baseline scenario (maintenance and replacement of ageing fleet) and two low-carbon scenarios (additional constraint of carbon dioxide emissions), according to vulnerability to temperature (vertical axis) and to wind and precipitation (horizontal axis) (analysis based on data from Atkins (2015), HM Treasury (2013a, 2013b), Metz (2014), National Grid (NG, 2014), Ofgem (2009) and URS (2010))

\subsection{Interdependencies}

Critical interdependencies between the energy sector and the water, transport and ICT sectors, although recognised, are not always effectively understood and assessed within the industry. To evaluate this issue, interviewees were asked to assess the importance of critical interdependencies between the energy sector and the water, transport and ICT sectors (Figure 5).

The water sector is seen as the most interdependent with energy, being mentioned by more than two-thirds of interviewees across the three communities. Interviewees believed that the interdependency with water will become even more significant in the long term and thus should be studied as a priority. Interviewed experts on engineering issues are aware of, and sometimes assess, "the dependency of thermal power stations on cooling water as well as the dependency of the water infrastructure on electricity'.

The ICT sector is seen as a critical interdependency for nearly two-thirds of interviewees from the investment sector. As an interviewed expert on investment issues argued: 'Every stage of the energy supply is dependent on ICT, from the operation of a generating asset to electricity balance on networks and future smart grids relying on smart metering at the distribution level'. ICT also depends on energy.
The transport sector is also considered a key interdependency - although less so in the engineering sector. As an interviewed expert on engineering issues noted, 'the interdependency has more to do with electrification of the rail network than with electric vehicles, which do not play a major role yet'.

However, most of the interviewees recognise that they have seldom assessed such interdependencies properly in energy infrastructure projects. To address this more efficiently, co-operation between sectors should be encouraged at a policy level and then cascaded down to the local level for implementation. Some bodies have recently been created with this responsibility in mind and are presented in more detail in Section 5 .

\subsection{Decision making}

\subsubsection{Types of adaptation actions and decision-making tools}

Adaptation actions and decision-making tools have been extensively developed in the literature; yet, not everyone is aware of or uses these tools, resulting in potentially divergent outcomes. A total of $86 \%$ of interviewees find the cost of adaptation action difficult to assess. As an interviewed expert on engineering issues summarised, 'the cost assessment of adaptation action is difficult to conduct because it has to be multi-criteria'. 


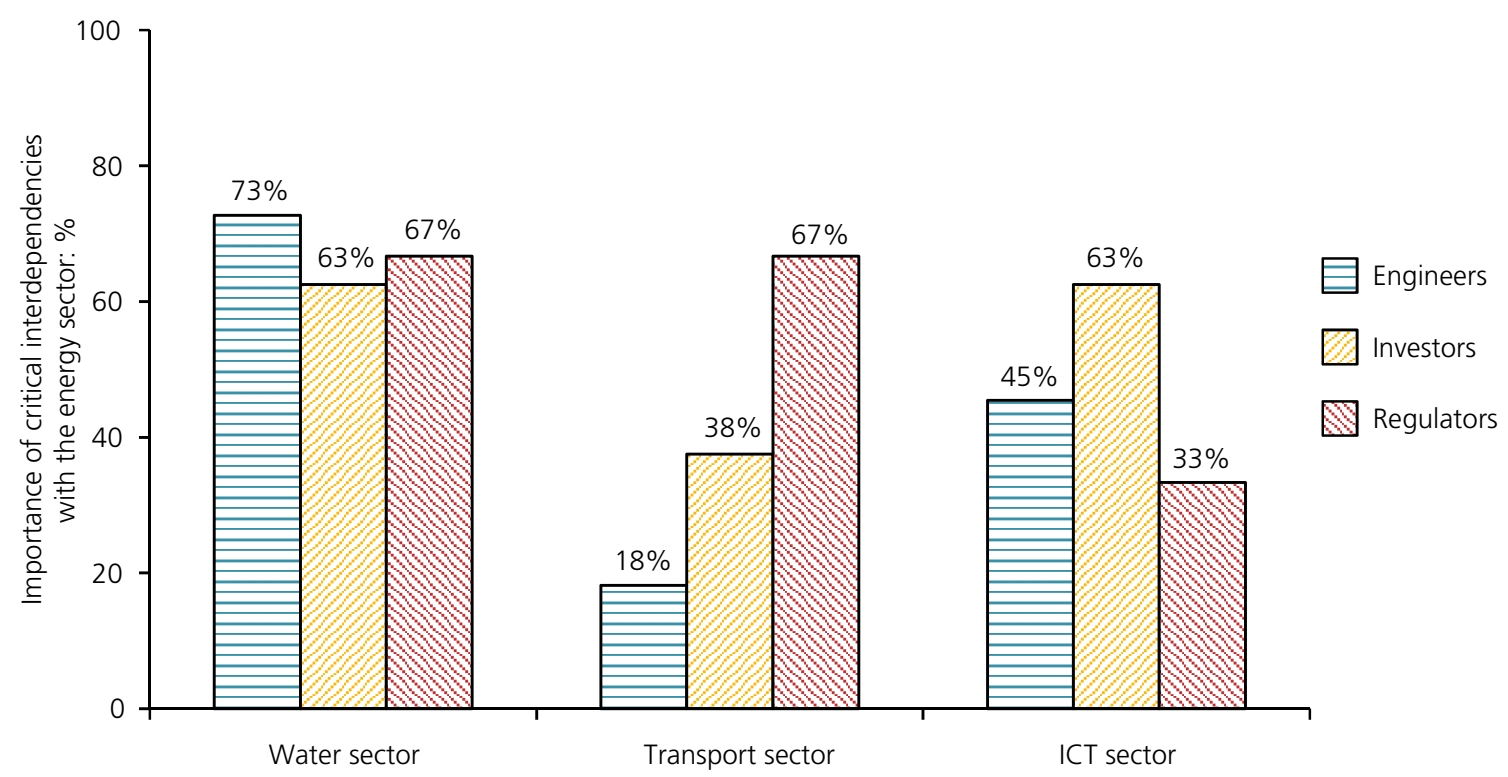

Figure 5. Proportion of interviewees who deemed critical interdependencies between the energy sector and the water, transport and ICT sectors to be important (Metz, 2014)

There are two categories of options for dealing with uncertainty: traditional appraisal of adaptation options (no-regret options, win-win options and low-regret options); and more complex decision-making tools (real options analysis and robust decision making). An option is called a no-regret option when the benefits exceed the costs regardless of the extent of future climate change; monitoring and modelling the climate is one example. An option is called a win-win option when it reduces vulnerability to climate change while having other social, economic or environmental benefits; enhancing and developing green urban spaces is one example. An option is called a low-regret option when the costs are relatively low as compared with the benefits related to future climate change; investing in research and development is one example.

Real options analysis is an extension of cost-benefit analysis, which includes flexibility and learning potential; such an approach includes optionality - that is, the ability to create additional value by expanding, contracting, abandoning or switching the asset during its lifetime (EEA, 2013; HM Treasury, 2009). It should be considered a complement to, not a substitute for, traditional discounted cash flow analysis (BEI, 2012; Van Putten and MacMillan, 2004). From an investor's viewpoint, a company's portfolio featuring affordable real options ensures a more solid resilience to the future. Robust decision making is a strategy that shields itself from large ranges of uncertainty. It uses a multi-criteria decision analysis in order to test options against uncertainty scenarios (Hall et al., 2012).
Most of the interviewees who are conscious of their decision making resort to more straightforward measures such as no-regret, win-win and low-regret options; very few use real options or robust decision making (Figure 6). Figure 6 features a noticeable exception for regulators, who seem much more aware of those different adaptation actions; yet they do not use those metrics on real projects - rather they only recommend that industry companies use them.

\subsubsection{Decision-making stages}

As illustrated in Figure 7, the two decision-making stages that are most affected by climate change adaptation are detailed design (for new assets) and asset life extension (for existing assets). As an interviewed expert on engineering issues explained, 'feasibility study is not affected by climate change because the strategic need for energy infrastructure is linked to other factors such as energy demand, economic growth, population growth'. However, during the detailed design phase, a site location can be rejected due to flood risk, and likewise moving an asset elsewhere can reduce the overall cost.

\subsection{Investment process}

\subsubsection{Shift in the sources of finance}

There has been a shift from traditional financing through large-scale utility companies and commercial banks, to a more complex financing environment featuring public institutions and different institutional investors (Figure 8). The 


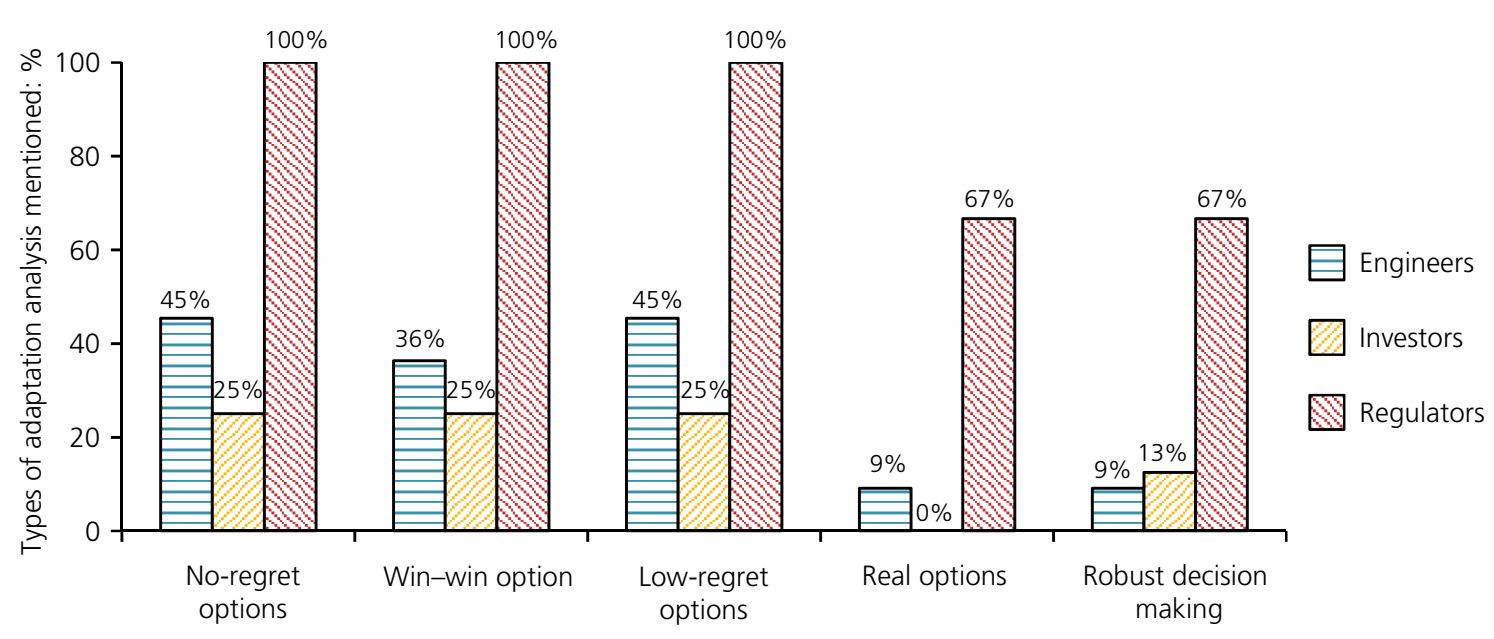

Figure 6. Types of adaptation analysis mentioned within sector groups by interviewees (Metz, 2014)

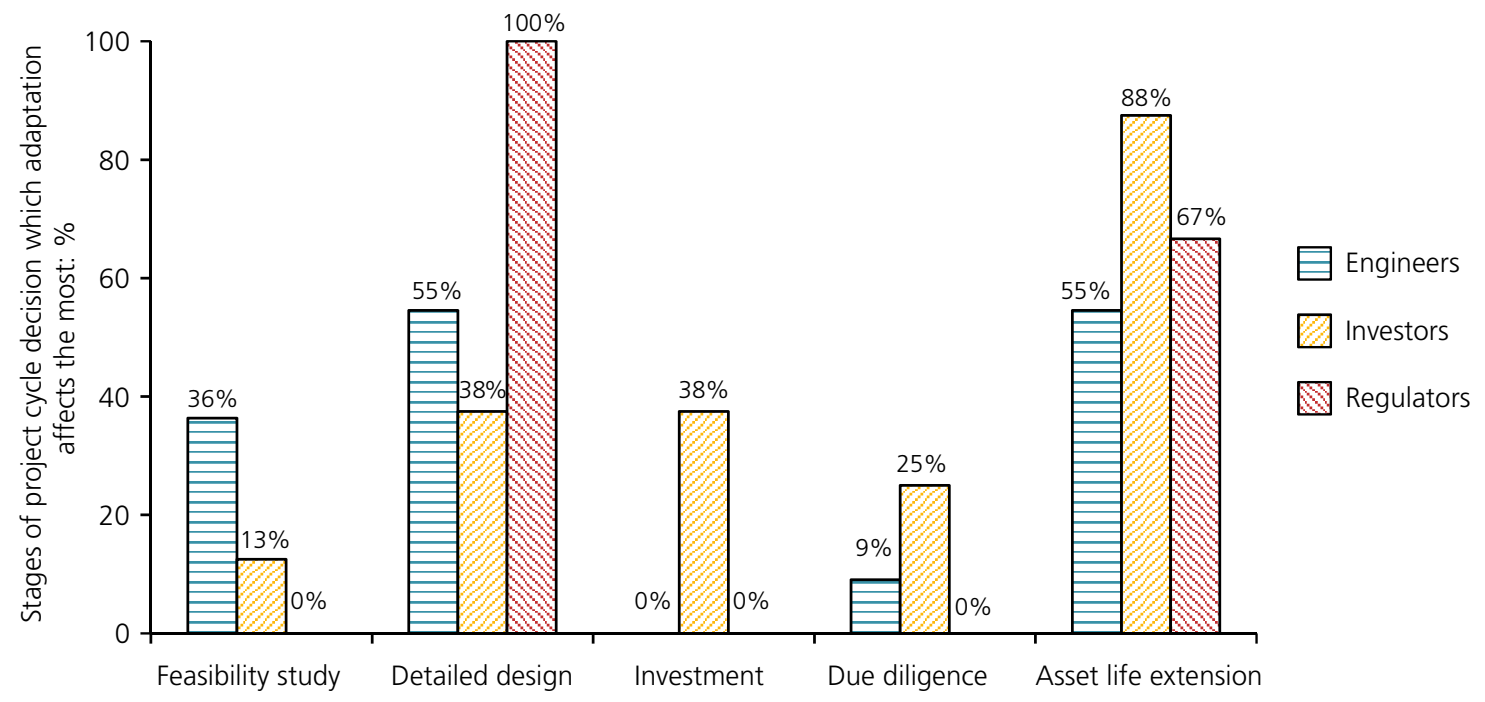

Figure 7. Stages of project cycle decision which adaptation affects the most according to interviewees (Metz, 2014)

interviewees made a clear distinction between (low-risk) regulated networks benefitting from price control, guaranteed revenue streams and access to low-rate debt loans; and (riskier) new-build generation assets with construction costs and less certain outcomes for which investors require higher returns on their capital. Many interviewees mentioned the anticipated decrease in investment from large-scale utility companies using the money on their balance sheet. While several interviewees mentioned small-scale utility companies as being future investors in the UK, none of them are expected to play a major role; they will remain focused on local investments, partly because they directly depend on subsidy mechanisms and the grid infrastructure becoming 'smart'. Institutional investors are expected to play a bigger role in future investment because they are targeting long-term assets featuring low risk and guaranteed returns.

\subsubsection{Lack of climate change expertise}

Investors generally suffer from a lack of climate change expertise and do not view climate change risks as a priority within 


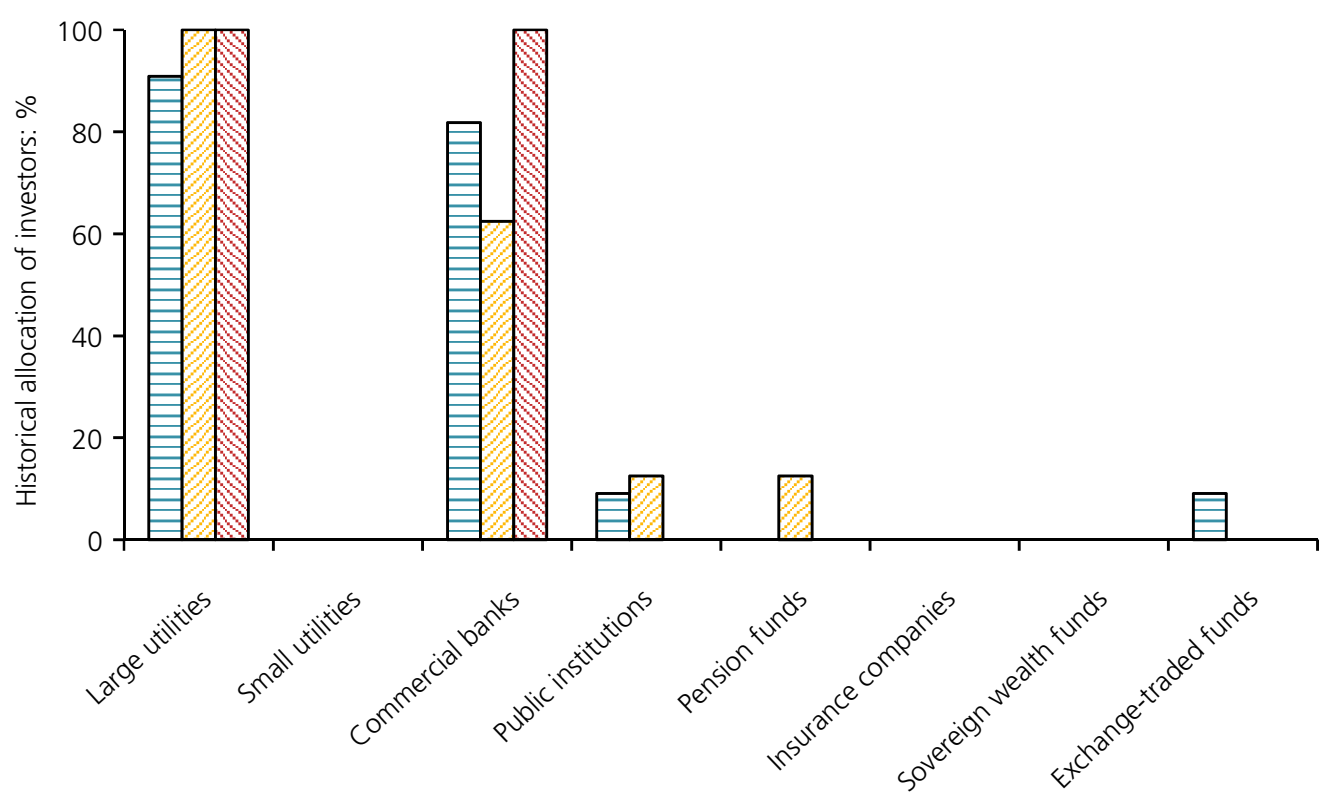

(a)

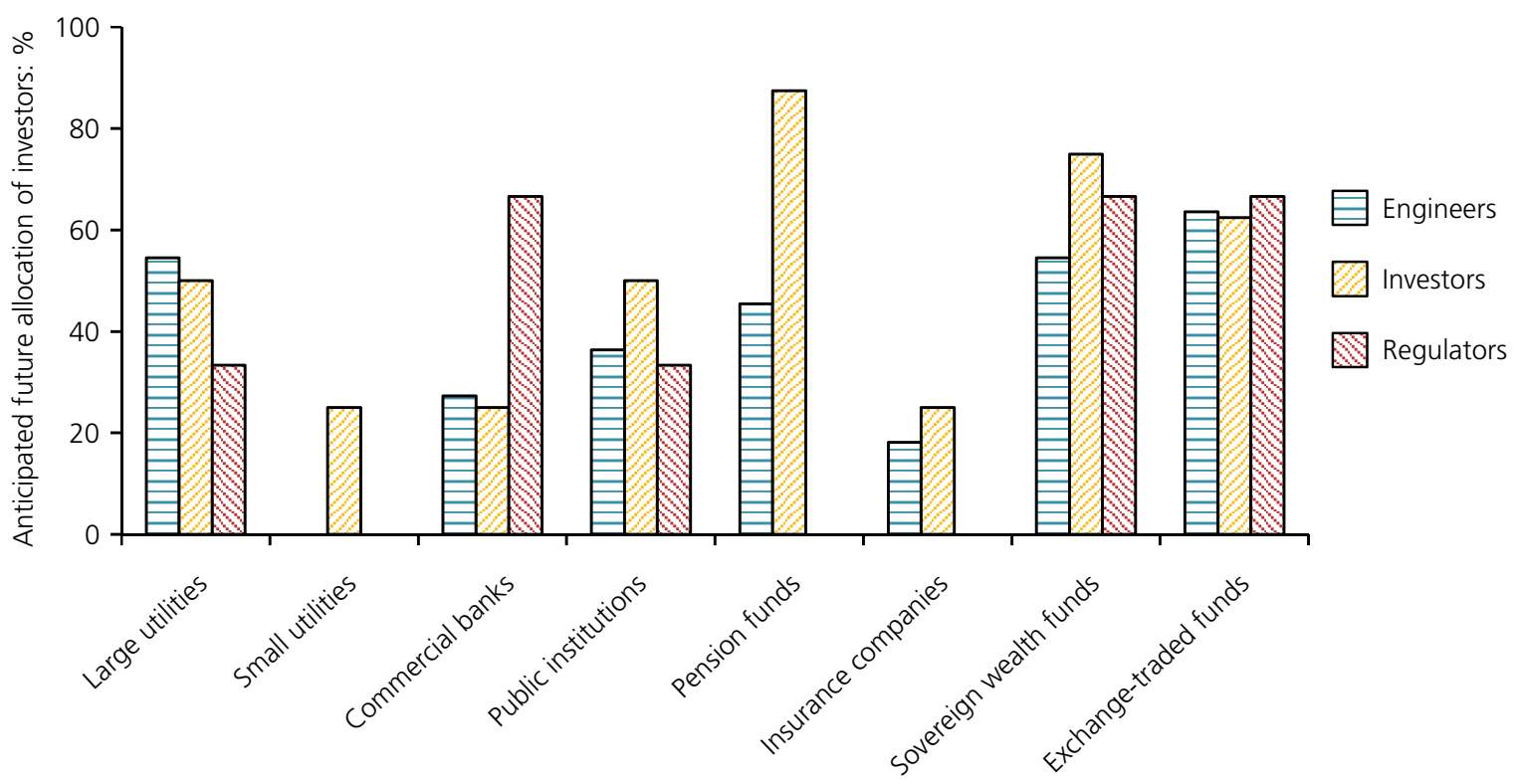

(b)

Figure 8. Historical (a) and anticipated future (b) allocation of investors in UK energy infrastructure according to interviewees (Metz, 2014)

their current investment risk framework. As an interviewed expert on investment issues pointed out, 'pension funds are investing in regulated networks because they offer revenue stability, but they are not willing to bear the construction risk of generation assets'. By contrast with sovereign wealth funds, pension funds are more willing to own $100 \%$ of the assets and manage them on their own. As an interviewed expert on investment issues argued, 'one of the main hindrances to institutional 
investor involvement in infrastructure is a lack of detailed expertise and knowledge about the practicalities of such projects'; it is for this reason that most sovereign wealth funds only take a small direct share in a project and partner with experienced investors that know the sector's characteristics well.

\subsubsection{Investor short-termism related to the investment process}

There is an embedded mindset of investor short-termism, caused by investment company business planning horizons which are often too short to entertain long-term climate change impacts (Llewellyn Consulting, 2013; OECD, 2011). Among those analysed by PwC (2009), only a few projects were able to secure design lives of more than 25 years; indeed, relatively short contract timescales limit the ability of the industry to make investments featuring payback periods which are longer than contract timescales (Sullivan et al., 2009). As an interviewed expert on investment issues pointed out, 'we tend to favour projects which span over relatively shorter timescales as the uncertainty of climate change impacts will be much lower'. Due to the uncertainty of climate change impacts, there is an overall reluctance to plan for the long term - that is, more than 50 years (URS, 2010).

\section{Considerations for policy}

In order for the necessary volume of investment to be realised in the UK energy sector and the needs of climate change to be accommodated, the following considerations are advised.

\subsection{Improve climate projections}

Different government bodies have worked with the Met Office to provide data on weather and climate change, with the UK Climate Projections 2009 and now the Environment Agency's Climate Ready Support Service being the leading measures. Further initiatives to fill gaps in climate data and to improve climate projections should be implemented by the government, potentially through the Environment Agency. Climate projections should include wind (speed and direction) as well as extreme weather events (storm and lightning). Such initiatives should help understand sensitivity of infrastructure to weather and climate.

\subsection{Identify and address interdependencies}

The next UK CCRA should focus on interdependencies and cascading effects; and the next National Adaptation Plan should respond to this. To ensure effective co-operation between sectors, the UK Regulators Network joins the UK's economic regulators together. Likewise, the Infrastructure Operators Adaptation Forum has been set-up by the Environment Agency's Climate Ready Support Service in order to join together regulators, government departments and infrastructure operators from across sectors. Its main role is to share information and explore a more consistent approach for longterm climate resilience.

\subsection{Standardise and enhance decision making}

\subsubsection{Types of adaptation actions and decision-making tools}

The Committee on Climate Change's Adaptation SubCommittee (CCC ASC, 2010, 2011, 2014), whose role is to provide independent, expert advice to the government on the preparedness of the UK for climate change and to report on progress, should spread the use of these decision-making tools. Regulators could have a role in prompting companies to resort to a wider variety of adaptation decision-making tools, potentially by developing a standardised approach to assess the costs, benefits and uncertainties of adaptation actions.

\subsubsection{Decision-making stages}

As recommended in the 2013 National Adaptation Programme report (Defra, 2013c), regulatory bodies should work with the Energy Networks Association to set design standards that include the entire spectrum of climatic changes, potentially using Engineering Technical Reports. As of 2015, the only adaptation report that has been produced addresses resilience to flooding of grid and primary substations (ENA, 2009). Developing further standards should help stakeholders dealing with climate change adaptation at the detailed design phase. Providing more information and data about future short-term climatic impacts should help companies make the right choice on whether they choose to extend an asset life or not.

\subsection{Nurture a supportive investment environment}

\subsubsection{Lack of climate change expertise}

Nearly $40 \%$ of interviewees from the investment community did not refer to any direct engagement with stakeholders to obtain a better understanding of climate change risks. This likely means that they either rely solely on their own knowledge or do not see these risks as important enough in the investment process. This situation could potentially change if a stronger expertise emerges within the investment community, as is currently happening within the engineering community.

The Adaptation Reporting Power was exercised in 2012 and has raised awareness of climate change impacts within the industry. However, the decision not to specify a prescribed format led to mixed results in terms of length and structure of the reports written by the reporting authorities (Cranfield University, 2012). Since the statutory guidance did not provide any particular methodology for assessing risks or developing a programme of adaptation measures, such an open approach makes it difficult to compare risks across organisations and sectors and to draw conclusions from the reports. However, the 
electricity companies coordinated activities through Energy UK and used a consistent methodology when reporting. In the second round, the Adaptation Reporting Power uses a voluntary approach to reporting. The way it will monitor adaptation action within the variety of stakeholders still needs to be assessed to ensure that infrastructure owners and operators, and their engineering consultants, systematically assess climate change impacts.

Hence, investors expect companies to have appropriate governance and risk management in place to enable them to conduct such reports. 'The Adaptation Reporting Power which forces certain companies to publicly report any adaptation measures is a leading example for other countries', an interviewed expert on investment issues argued.

A regulatory framework that attracts and encourages private sector entities to develop the necessary expertise should be created; potentially through a collaboration between UK public institutions and the Green Investment Bank supported by HM Treasury. In return, engineering companies and investors should ensure they build the right in-house skills.

\subsubsection{Investor short-termism}

UK government policy needs to communicate a clear longterm vision by way of government bodies such as Infrastructure UK to encourage long-horizon investment and limit short-termism. HM Treasury took proactive measures when releasing their first National Infrastructure Plan in 2010 and their first detailed pipeline of scheduled projects in 2013, as well as setting up Infrastructure UK to communicate a clear vision of how and when the infrastructure should be adapted.
Such initiatives should not only remain aspirational, but a closer link to real future projects should also be developed. If implemented, a national, government-owned investment bank could be integrated into Infrastructure UK and offer a longterm vision for infrastructure.

The UK government needs to understand that policy stability is a key requirement to attract investment in the UK energy sector. Government bodies such as Infrastructure UK should communicate a clear long-term vision and develop a culture of proactive leadership and innovation. In terms of regulation, the Adaptation Reporting Power should raise awareness of climate change impacts within the industry, educate investors about the long-term effects of excessive short-termism behaviour and introduce incentives to encourage longer-term thinking.

\section{Summary of the research}

\subsection{Key findings}

The research and interview phases helped assess the extent to which key issues identified have been, or are being, addressed by academics, industry and regulatory bodies (Table 1). The key points of the analysis are summarised as follows. (a) There is a lack of confidence in future projections of wind (speed and direction) as well as extreme weather events (storm and lightning). (b) Critical interdependencies between the energy sector and the water, transport and ICT sectors, although recognised, are not always effectively understood and assessed within the industry. (c) Adaptation actions and decision-making tools have been extensively developed in the literature; yet, not everyone is aware of or uses these tools, resulting in potentially divergent outcomes. $(d)$ The two decision-making stages that are most affected by climate change adaptation are detailed

(a) Lack of confidence in climate projections of wind and extreme weather events

(b) Critical interdependencies between the energy sector and the water, transport and ICT sectors

(c) Utilisation of adaptation actions and decision-making tools

(d) Decision-making stages most affected by climate change adaptation

(e) Shift in the sources of finance for energy infrastructure projects

(f) Lack of climate change expertise among investors in energy infrastructure projects

(g) Investor short-termism in a context of long-term climate change impacts

$\begin{array}{lll}\text { Academics } & \text { Industry } & \text { Regulation } \\ \text { Yellow } & \text { Red } & \text { Yellow } \\ \text { Green } & \text { Red } & \text { Yellow } \\ & & \\ \text { Green } & \text { Red } & \text { Red } \\ \text { Red } & \text { Yellow } & \text { Red } \\ \text { Yellow } & \text { Green } & \text { Red } \\ \text { Yellow } & \text { N/A } & \text { Red } \\ \text { Red } & \text { N/A } & \text { Red }\end{array}$

Red, issue has not yet been addressed and is not on the way to being addressed; yellow, issue has been partially addressed or is on the way to being partially addressed; green, issue has already been mostly addressed, on the way to being addressed; N/A, issue is not applicable

Table 1. Research issues addressed by academics, industry and regulatory bodies, based on the interviews conducted (Atkins, 2015; Metz, 2014) 
design (for new assets) and asset life extension (for existing assets). (e) There is a shift in the sources of finance, from traditional financing to a more complex environment featuring public institutions and institutional investors. $(f)$ Investors generally suffer from a lack of climate change expertise and do not view climate change risks as a priority within their current investment risk framework. ( $g$ ) There is an embedded mindset of investor short-termism, caused by investment company business planning horizons, which are often too short to entertain long-term climate change impacts.

\subsection{Considerations for policy}

In order for the necessary volume of investment to be realised in the UK energy sector and the needs of climate change to be accommodated, the following considerations are advised. (a) Further initiatives to improve climate projections of wind and extreme weather events should be implemented by the government, potentially through the Environment Agency. (b) The next UK CCRA should focus on interdependencies and the next National Adaptation Plan should further enforce co-operation between regulators, government departments and infrastructure operators across sectors - for example, through the UK Regulators Network or the Infrastructure Operators Adaptation Forum. (c) The Committee on Climate Change's Adaptation Sub-Committee and regulators could have a role in prompting companies to resort to a wider variety of adaptation decision-making tools, potentially by developing a standardised approach to assess the cost of adaptation actions. (d) Regulatory bodies should work with the Energy Networks Association to set a range of design standards that include the entire spectrum of climatic changes, potentially using Engineering Technical Reports. (e) Improving accuracy in future short-term climate projections and impacts should help companies make the right choice on whether they extend an asset life or not. $(f)$ The Adaptation Reporting Power should provide more structured reporting guidance to ensure that infrastructure owners and operators, and their engineering consultants, systematically assess climate change impacts. ( $g$ ) A regulatory framework that attracts and encourages private sector entities to develop the necessary climate change expertise should be created, potentially by way of collaboration between UK public institutions and the Green Investment Bank supported by HM Treasury. In return, engineering companies and investors should ensure they build the right in-house skills. (h) A clear long-term vision for UK energy policy needs to be developed and communicated through government bodies such as Infrastructure UK.

\section{Conclusion}

The risks arising from climate change and infrastructure interdependencies require that the UK energy infrastructure builds an adaptive capacity for the future. To ensure that climate change adaptation is included in energy investment, further progress by engineering, investment and regulatory sectors will need to be supported by policy instruments. Such practical recommendations could be used by the UK government when implementing new policy and regulation for the energy industry. The goal is to facilitate and finance the necessary improvements to the UK electricity and natural gas supply structure to ensure adequate supplies while adapting to climate change.

\section{Acknowledgements}

The authors acknowledge Atkins for supporting AM's research project and all the interviewees who offered their valuable time and perspectives on these timely issues. Any views expressed are those of the authors and not of any organisations they represent.

\section{REFERENCES}

Atkins (2015) UK Energy Supply Infrastructure DecisionMaking Processes in the Context of Climate Change Adaptation and Investment Needs Under Uncertainty: Considerations for Policy. Atkins, London, UK.

BEI (Banking Environment Initiative) (2012) An Options Approach to Unlocking Investment in Clean Energy. BEI, Cambridge, UK.

CCC ASC (Committee on Climate Change - Adaptation Sub-Committee) (2010) How Well Prepared is the UK for Climate Change? CCC ASC, London, UK.

CCC ASC (2011) Adapting to Climate Change in the UK: Measuring Progress. CCC ASC, London, UK. CCC ASC (2014) Managing Climate Risks to Well-Being and the Economy. CCC ASC, London, UK.

Cimato F and Mullan M (2010) Adapting to Climate Change, Analysing the Role of Government. Department for Environment, Food \& Rural Affairs, London, UK. Climate Change Act 2008 (2008) Elizabeth II. Chapter 27. Her Majesty's Stationery Office, London, UK.

Cranfield University (2012) Evaluating the Risk Assessment of Adaptation Reports Under the Adaptation Reporting Power: Final Summary. Centre for Environmental Risks and Futures, Cranfield University, Cranfield, UK.

DECC (Department of Energy and Climate Change) (2010) Digest of United Kingdom Energy Statistics (DUKES). DECC, London, UK. See http://www.decc.gov.uk/en/ content/cms/statistics/publications/dukes/dukes.aspx (accessed 07/07/2015).

DECC (2011a) National Policy Statements for Energy Infrastructure. DECC, London, UK. See http://www.gov. uk/government/publications/national-policy-statements-forenergy-infrastructure (accessed 07/07/2015).

DECC (2011b) Overarching National Policy Statement for Energy (EN-1). DECC, London, UK. 
DECC (2012a) Digest of United Kingdom Energy Statistics (DUKES). DECC, London, UK. See http://www.gov.uk/ government/uploads/system/uploads/attachment_data/ file/65881/5949-dukes-2012-exc-cover.pdf (accessed 07/07/2015).

DECC (2012b) UK Energy Sectors Indicators - Economic Indicators Spreadsheet. DECC, London, UK. See http:/l www.gov.uk/government/publications/uk-energy-sectorindicators-2012 (accessed 07/07/2015).

DECC (2013a) Digest of United Kingdom Energy Statistics Chapter 5: Electricity. DECC, London, UK. See http:/l www.gov.uk/government/publications/electricity-chapter-5digest-of-united-kingdom-energy-statistics-dukes (accessed 07/07/2015).

Defra (Department for Environment, Food \& Rural Affairs) (2011) Climate Resilient Infrastructure: Preparing for a Changing Climate. Defra, London, UK.

Defra (2012a) Climate Change Risk Assessment for the Energy Sector. Defra, London, UK.

Defra (2012b) Climate Change Risk Assessment: Evidence Report. Defra, London, UK.

Defra (2012c) Climate Change Risk Assessment: Government Report. Defra, London, UK.

Defra (2013a) Adapting to Climate Change: Ensuring Process in Key Sectors. Defra, London, UK.

Defra (2013b) The Economics of Climate Resilience - Buildings and Infrastructure Theme: UK Power Generation and Transmission. Defra, London, UK.

Defra (2013c) The National Adaptation Programme: Making the Country Resilient to a Changing Climate. Defra, London, UK.

EEA (European Environment Agency) (2013) Adaptation in Europe: Addressing Risks and Opportunities from Climate Change in the Context of Socio-Economic Developments. EEA, Copenhagen, Denmark.

ENA (Energy Networks Association) (2009) Engineering Technical Report-ETR 138: Resilient to Flooding of Grid and Primary Substations. ENA, London, UK.

Gillham B (2000) The Research Interview. Continuum, London, UK.

Hall J, Lempert R, Keller K et al. (2012) Robust climate policies under uncertainty: a comparison of robust decision making and info-gap methods. Risk Analysis 32(10): 1657-1672.

HM Treasury (2009) Accounting for the Effects of Climate Change: Supplementary Green Book Guidance. HM Treasury, London, UK.

HM Treasury (2012) National Infrastructure Plan. HM Treasury and Infrastructure UK, London, UK.

HM Treasury (2013a) National Infrastructure Pipeline Spreadsheet. HM Treasury, London, UK. See http://www. gov.uk/government/publications/national-infrastructureplan-2013 (accessed 07/07/2015).
HM Treasury (2013b) National Infrastructure Plan. HM Treasury and Infrastructure UK, London, UK.

Hoggart K, Lees L and Davies A (2002) Researching Human Geography. Arnold, London, UK.

IPCC (Intergovernmental Panel on Climate Change) (2013) Climate Change 2013: the Physical Science Basis. Contribution of Working Group I to the Fifth Assessment Report of the Intergovernmental Panel on Climate Change (Stocker TF, Qin D, Plattner GK et al. (eds)). Cambridge University Press, Cambridge, UK.

IPCC (2014) Climate Change 2014: Impacts, Adaptation, and Vulnerability. Part A: Global and Sectoral Aspects. Contribution of Working Group II to the Fifth Assessment Report of the Intergovernmental Panel on Climate Change (Field CB, Barros VR, Dokken DJ et al. (eds)). Cambridge University Press, Cambridge, UK.

ITRC (Infrastructure Transitions Research Consortium) (2014) National Infrastructure Assessment: Analysis of Options for Infrastructure Provision in Great Britain. UK Infrastructure Transitions Research Consortium and University of Oxford, Oxford, UK.

Llewellyn Consulting (2013) UK Infrastructure: The Challenges for Investors and Policymakers. Llewellyn Consulting and Pension Insurance Corporation, London, UK.

Metz A (2014) UK Energy Supply Infrastructure Decision-Making Processes in the Context of Climate Change Adaptation and Investment Needs Under Uncertainty: Considerations for Policy. Master's thesis. Imperial College London, London, UK.

NG (National Grid) (2010a) Climate Change Adaptation Report: Impacts on Electricity Network. National Grid, London, UK.

NG (2010b) Climate Change Adaptation Report: Impacts on Gas Network. National Grid, London, UK.

NG (2014) UK Future Energy Scenarios: UK Gas and Electricity Transmission. National Grid, London, UK.

OECD (Organisation for Economic Co-operation and Development) (2011) Private Sector Engagement in Adaptation to Climate Change: Approaches to Managing Climate Risks. OECD, Paris, France.

Ofgem (Office of Gas and Electricity Markets) (2009) Project Discovery - Energy Market Scenarios. Ofgem, London, UK.

ONS (Office for National Statistics) (2010) Annual Business Inquiry 1995-2007 National Results - Spreadsheet. ONS, London, UK. See http://www.ons.gov.uk/ons/rel/abs/ annual-business-inquiry/1995-2007-national/index.html (accessed 07/07/2015).

ONS (2014) Annual Business Survey 2008-2012 - Spreadsheet. ONS, London, UK. See http://www.ons.gov.uk/ons/rel/abs/ annual-business-survey/index.html (accessed 07/07/2015).

PwC (PricewaterhouseCoopers) (2009) Adapting to Climate Change: the Role of Public Procurement. PwC, London, UK. 
PwC (2010) Adapting to Climate Change in the Infrastructure Sectors: Maintaining Robust and Resilient Infrastructure Systems in the Energy, Transport, Water and ICT Sectors. PwC, London, UK.

Saunders M, Lewis P and Thornhill A (2002) Research Methods for Business Students. FT Prentice Hall, London, UK. pp. 247-270.

Sullivan R, Russell D, Beloe S, Curtiss F and Firth J (2009) Managing the Unavoidable: Investment Implications of a Changing Climate. Acclimatise, Newark; Henderson Global Investors, London; Insight Investment, London;
RAILPEN Investments, London; and Universities Superannuation Scheme, Liverpool, UK.

UKCP09 (UK Climate Projections 2009) (2009) UKCP09 Briefing Report. UKCP09, London, UK.

URS (United Research Services Corporation) (2010) Adapting Energy, Transport \& Water Infrastructure to the Long-term Impacts of Climate Change. URS, London, UK.

Van Putten AB and MacMillan IC (2004) Making Real Options Really Work. Harvard Business Review, Watertown, MA, US. WEF (World Economic Forum) (2014) Climate Adaptation:

Seizing the Challenge. WEF, Geneva, Switzerland.

\section{WHAT DO YOU THINK?}

To discuss this paper, please email up to 500 words to the editor at journals@ice.org.uk. Your contribution will be forwarded to the author(s) for a reply and, if considered appropriate by the editorial panel, will be published as discussion in a future issue of the journal.

Proceedings journals rely entirely on contributions sent in by civil engineering professionals, academics and students. Papers should be 2000-5000 words long (briefing papers should be 1000-2000 words long), with adequate illustrations and references. You can submit your paper online via www.icevirtuallibrary.com/content/journals, where you will also find detailed author guidelines. 